\title{
ASSESSMENT OF CARDIAC FUNCTION IN PATIENTS WITH CHRONIC MYELOID LEUKEMIA TREATED WITH IMATINIB AT THE NATIONAL CENTER OF HEMATOLOGY
}

\author{
YASSEN MOHI ALDEEN TAHER ${ }^{1}$, ADEEB ABBAS AHMED ALSHAMI ${ }^{2}$, HAYDER ADNAN FAWZI ${ }^{3 *}$, NADHIM \\ SHALAAN $^{4}$, ALAA FADHIL ALWAN ${ }^{5}$
}

${ }^{1}$ Department of Medicine, Al Iraqia University, College of Medicine, Iraq. ${ }^{2}$ Department of Internal Medicine, The National Center of Hematology, Mustansiriyah University, Iraq. ${ }^{3}$ Department of Clinical Pharmacy, Medical City Complex, Baghdad Teaching Hospital, Iraq. ${ }^{4}$ Department of Cardiology, Al-Yarmouk Teaching Hospital, Baghdad, Iraq. ${ }^{5}$ Department of Haematology, The National Center of Hematology, Mustansiriyah University, Iraq. Email: hayder.adnan2010@ierit.nahrainuniv.edu.iq

Received: 02 May 2018, Revised and Accepted: 06 June 2018

ABSTRACT

Objective: The objective was to study the assessment of the possible cardiotoxic effect of imatinib using echocardiography.

Methods: Prospective study included 50 patients that treated at the National Hematology Center of Al-Mustansiriya University from May 2008 to December 2009, echocardiography was used to measure the cardiac ejection fraction accurately, indices of ventricular ejection and relaxation and measurement of left ventricular internal diameter in diastole and (LVIDd) at baseline and after 12 months.

Results: 24 (41\%) were men and 26 (59\%) were women. Their ages ranged from 18 to 74 years, with a median age of 36.8 years. At baseline, mean EF was $0.63 \pm 0.057$ and after 12 months; mean EF was $0.64 \pm 0.068(\mathrm{p}>0.05)$. Mean peak emptying rate at baseline was $3.23 \pm 0.5 \mathrm{ED} / \mathrm{s}$, and after 1 year was $3.21 \pm 0.5 \mathrm{ED} / \mathrm{s}(\mathrm{p}>0.05)$. Time to peak filling rate at baseline was $144 \pm 26 \mathrm{~ms}$, and after 1 year was $143 \pm 25 \mathrm{~ms}$ ( $p>0.05)$. There is a significant inverse trend for both LVIDd and LVID in systole (LVIDs) reduced as age increase; the female had significantly lower LVIDd and LVIDs compared to male.

Conclusion: We find no evidence of significant impairment in cardiac function over 12 months of imatinib treatment. Advancing age associated with reduced cardiac performance for patients receiving imatinib.

Keywords: Imatinib, Cardiotoxicity, Echocardiology, Chronic myeloid leukemia.

(C) 2018 The Authors. Published by Innovare Academic Sciences Pvt Ltd. This is an open access article under the CC BY license (http://creativecommons. org/licenses/by/4. 0/) DOI: http://dx.doi.org/10.22159/ajpcr.2018.v11i10.27059

\section{INTRODUCTION}

Imatinib has transformed the outlook for chronic myeloid leukemia (CML) and gastrointestinal stromal tumor. In CML, the majority of chronic phase patients remain well with complete cytogenetic responses after 8 years of treatment [1], with excellent quality of life, in sharp contrast to interferon alfa, the previous standard of care [2]. The 5-year survival rate is $90 \%$ with optimal therapy [3]. In 2008, the majority of patients diagnosed with chronic phase myeloid leukemia can expect to have durable responses with good quality of life. From $20 \%$ to $30 \%$ of patients who fail for imatinib treatment, second-line treatments are an effective salvage strategy [4]. The first report of imatinib causing cardiac problems was in 2006, documenting ABLmediated impairment of cardiacmyocyte function in culture, and citing 10 patients who developed cardiac failure while receiving imatinib [5]. This was clinically unanticipated and created considerable alarm among patients. However, most of these 10 patients had relevant comorbidities and most responded well to standard heart failure regimens [6].

In the pivotal phase III International Randomized Study of Interferon and STI571 (IRIS) trial, primary resistance observed in $24 \%$ of patients, and secondary resistance presented as relapse in $17 \%$ of patients and disease progression in $7 \%$ after 4.5 years [7]. After 6 years, 34\% of patients had discontinued imatinib treatment, mostly (14\%) because of an unsatisfactory therapeutic effect (defined as lack of efficacy/progression), but a number of patients (5\%) also stopped receiving the drug as a result of adverse events (AEs) or abnormal laboratory values [8]. Although rare, severe congestive heart failure (CHF) and left ventricular dysfunction have reported during imatinib treatment, especially in patients with risk factors or comorbidities. In the IRIS trial, this observed in $0.7 \%$ of patients [7]. Cardiotoxicity associated with high-dose imatinib was not reported during the START-R study [9]. In a large review of patients enrolled in imatinib clinical studies $(\mathrm{n}=1.276), 1.8 \%$ of patients had symptoms suggestive of systolic heart failure. Most had risk factors for cardiac failure. In total, $0.6 \%$ of patients had cardiac events attributed to imatinib treatment [10].

The mechanism underlying imatinib-induced cardiac failure is currently unclear. In an in vitro study, physiological concentrations of imatinib significantly and adversely affected mitochondrial membrane potential, apoptosis, cell viability, and cellular ultrastructure [11]. This cardiotoxic effect may link to inhibition of BCR-ABL. Imatinib was reported to cause stress-induced and dose-dependent mitochondrial changes in murine ventricular myocytes, which reduced by re-engineering the imatinib molecule such that BCR-ABL inhibition was hampered [5]. We have therefore conducted a prospective assessment of cardiac function for CML patients on imatinib therapy.

\section{Patients and methods}

Between May 2008 and December 2009, 50 patients with CML treated at the National Center of Hematology; Al-Mustansiriya University included in this study. All patients received Imatinib (Gleevec ${ }^{\circledR}$; Novartis Pharmaceuticals Corporation, New Jersey, USA) $400 \mathrm{mg}$ /day. All patients gave informed written consent, and the study performed in accordance with Helsinki Declaration for clinical research, the study approved by the college of medicine - Mustansiriyah University. The criterion for entry into the study was a treatment for CML with imatinib at any dose for at least 12 months. Entry offered to all 50 eligible patients at our center. Two patients had subsequently lost hematological remission and were being treated either with an increased dose of imatinib to 600 or by adding hydroxyurea because of lack of second-generation tyrosine kinase inhibitor (dasatinib or nilotinib). All other patients required no or 
minimal dose interruption. All patients subjected to a complete medical history including detailed cardiac history. Furthermore, all serious AEs in these patients were reviewed, with particular attention to that related to cardiac origin. These included shortness of breath, dyspnea, chest pain, arrhythmia, cardiac events, myocardial infarction, angina, pleural effusion, and peripheral edema. Physical examination, a 12-lead electrocardiogram (ECG) and echocardiography are done to all patients.

Echocardiography was used to accurately measure the cardiac ejection fraction (EF; normal range $0.55-0.71$ at our center), together

Table 1: Treatment characteristics at study entry and during follow-up

\begin{tabular}{ll}
\hline Variables & Value, n (\%) \\
\hline Treatment and dose at study entry & \\
Imatinib 400 mg daily & $44(88)$ \\
Imatinib 600mg daily & $6(12)$ \\
Treatment changes during follow-up & \\
Unchanged & $48(96)$ \\
Imatinib 400 daily to imatinib 600 & $1(2)$ \\
Imatinib 400 daily to & $1(2)$ \\
imatinib+hydroxyurea & \\
\hline
\end{tabular}

with indices of ventricular ejection and relaxation and to measure left ventricular internal diameter in diastole (LVIDd; normal value $<5.8 \mathrm{~cm}$ ) and in systole (LVIDs; normal value $<4.5 \mathrm{~cm}$ ), since left ventricular dilatation may be an early feature of heart failure. Second echocardiography performed after a further 12 months. Subgroup analysis was carried out according to gender, age, and duration of imatinib treatment. Independent t-test and one-way ANOVA with trend used to analyze the statistical significance, $p \leq 0.05$ was considered statistically significant, all analysis performed using GraphPad Prism 7.0 software package.

\section{RESULTS}

Of the 50 patients evaluated, $24(41 \%)$ were men and $26(59 \%)$ were women. Their ages ranged from 18 to 74 years, with a median age of 36.8 years. In 2 patients (4\%), the time interval between the diagnosis of CML and the initiation of imatinib therapy was longer than 1 month; in 48 patients (96\%), this time was 1 month or shorter. The mean duration of imatinib treatment before enrolment was $3.4 \pm 1.8$ years. Pre-existing diagnoses relevant to the cardiovascular system included hypertension ( 4 patients), obesity ( 3 patients), smoking ( 2 patients), type 2 diabetes mellitus ( 1 patient), and angina ( 1 patient), all of which predated the diagnosis of CML.

Table 2: Subgroup analysis according to gender, age, and duration of treatment

\begin{tabular}{|c|c|c|c|c|}
\hline Subgroups & No. & $\mathrm{EF}($ mean $\pm S D)$ & LVIDd (mean \pm SD) & LVIDs (mean \pm SD) \\
\hline \multicolumn{5}{|l|}{ Age (years) } \\
\hline $5-25$ & 7 & $0.63 \pm 0.035$ & $5.40 \pm 0.00$ & $3.55 \pm 0.21$ \\
\hline $26-35$ & 18 & $0.62 \pm 0.037$ & $5.35 \pm 0.26$ & $3.2 \pm 0.28$ \\
\hline $36-45$ & 11 & $0.65 \pm 0.047$ & $5.18 \pm 0.36$ & $3.48 \pm 0.48$ \\
\hline $46-55$ & 9 & $0.62 \pm 0.059$ & $5.16 \pm 0.34$ & $3.30 \pm 0.45$ \\
\hline $56-65$ & 3 & $0.64 \pm 0.074$ & $4.58 \pm 0.69$ & $2.70 \pm 0.41$ \\
\hline $66-75$ & 2 & $0.65 \pm 0.068$ & $4.94 \pm 0.94$ & $2.99 \pm 0.68$ \\
\hline \multicolumn{5}{|l|}{ Gender } \\
\hline Male & 24 & $0.63 \pm 0.051$ & $5.38 \pm 0.42$ & $3.41 \pm 0.49$ \\
\hline Female & 26 & $0.64 \pm 0.063$ & $4.83 \pm 0.58$ & $2.99 \pm 0.47$ \\
\hline $\mathrm{p}$ value & 50 & 0.542 & $0.0004[\mathrm{~S}]$. & $0.003[\mathrm{~S}]$. \\
\hline \multicolumn{5}{|c|}{ Duration of imatinib treatment (years) } \\
\hline $0-1$ & 5 & $0.63 \pm 0.050$ & $5.10 \pm 0.30$ & $3.28 \pm 0.33$ \\
\hline$>1-2$ & 5 & $0.65 \pm 0.075$ & $4.73 \pm 0.90$ & $2.90 \pm 0.62$ \\
\hline$>2-3$ & 10 & $0.62 \pm 0.057$ & $4.96 \pm 0.50$ & $3.08 \pm 0.47$ \\
\hline$>4-5$ & 8 & $0.65 \pm 0.054$ & $5.24 \pm 0.26$ & $3.17 \pm 0.33$ \\
\hline$>5-6$ & 8 & $0.63 \pm 0.061$ & $5.42 \pm 0.57$ & $3.48 \pm 0.59$ \\
\hline$>6-7$ & 4 & $0.60 \pm 0.040$ & $4.83 \pm 0.42$ & $3.13 \pm 0.40$ \\
\hline $\mathrm{p}$ value & 50 & 0.454 & 0.464 & 0.491 \\
\hline
\end{tabular}

LVIDd: Left ventricular internal diameter in diastole, LVIDs: Left ventricular internal diameter in systole

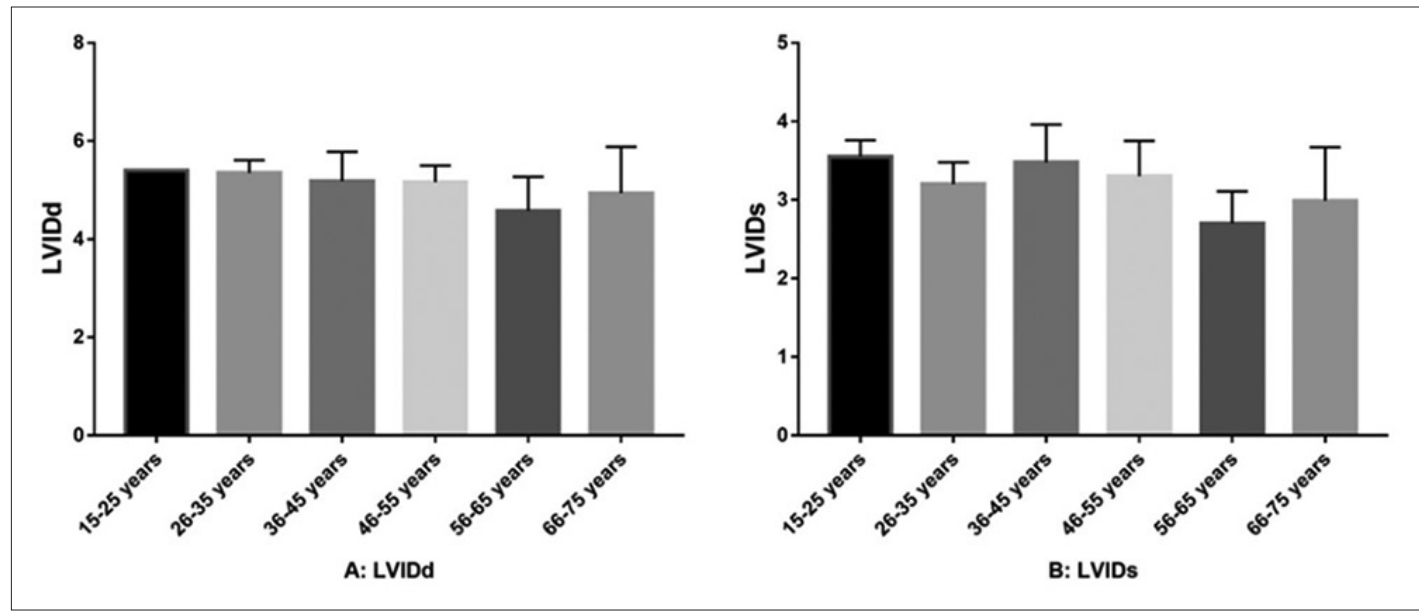

Fig. 1: Left ventricular internal diameter in diastole (LVIDd) and LVID in systole distribution according to age 
Resting ECG recordings taken at baseline were normal for 47 patients, three had voltage criteria for left ventricular hypertrophy, and two had evidence of limited previous myocardial infarction. Echocardiography identified aortic sclerosis in four and mitral valve prolapse in one participant. Two patients had baseline EF values on echocardiography that was below normal $(<0.55)$. One of these patients had a history of mild dilated cardiomyopathy, documented by echocardiography, before the diagnosis of CML and initiation of imatinib treatment. This patient had a baseline EF of 0.52 and LVIDd of $6.8 \mathrm{~cm}$. One patient with hypertensive heart disease had an EF of 0.48 and LVIDd of $5.7 \mathrm{~cm}$. Neither of these patients showed any significant change in cardiac condition or imaging values during the 1-year follow-up (Table 1).

There significant inverse trend for both LVIDd and LVIDs reduced as age increase, the female had significantly lower LVIDd and LVIDs compared to male, as illustrated in Table 2 and Fig. 1.

\section{DISCUSSION}

At entry to the study, mean $\mathrm{EF}$ for the 50 patients was $0.63 \pm 0.057$. Mean LVIDd was $5.09 \pm 0.58 \mathrm{~cm}$ after 12 months follow-up; mean EF obtained by echocardiography was $0.64 \pm 0.068$, which is not significantly different from the mean baseline EF. Mean peak emptying rate at entry was $3.23 \pm 0.5 \mathrm{ED} / \mathrm{s}$, and after 1 year was $3.21 \pm 0.5 \mathrm{ED} / \mathrm{s}$. Time to peak filling rate at entry was $144 \pm 26 \mathrm{~ms}$, and after 1 year was $143 \pm 25 \mathrm{~ms}$. There was no significant difference between any of the echocardiographic measurements when compared at baseline and after 1-year followup. Our findings were in agreement with Druker et al., in which they reported only one patient $(<1 \%)$ having CHF after a follow-up period of 60 months [7], and in agreement with a more recent study in which all patients after 1-year follow-up did not show cardiotoxicity [12]. In the current study advanced age appear to negatively influence cardiac function in which both LVIDd and LVIDs reduced significantly with advancing age, our findings were in agreement with Maharsy et al. study in which they found that imatinib-induced cardiotoxicity in rat is age-dependent [13], this effect of imatinib on cardiac cells mediated through the inhibition of cardiomyocyte cAbl and activation of the JunK pathway [13].

The present study has two findings that are reassuring to CML patients and their clinicians. First, in a prospective approach designed to detect evidence of myocardial dysfunction, we have found no proof of this except in patients with pre-existing cardiac problems. Second, an assessment with an interval of 12 months revealed no evidence of any deterioration in myocardial function, despite the continuation of imatinib. The present data, therefore, add to and extend the currently available data on cardiac function in patients receiving imatinib treatment. Using echocardiography, a sensitive indicator of left ventricular performance, we find no evidence of significant impairment in cardiac function over 12 months of imatinib treatment. The result of the current study is consistent with previous reports and will reassure CML patients and their physicians on the cardiac safety of imatinib. Imatinib remains a safe and invaluable drug that is rightly the gold standard of CML care. Studies should, therefore, continue whether it can sustain long-term disease control.

\section{CONCLUSION AND RECOMMENDATION}

There is no evidence of significant impairment in cardiac function over 12 months of imatinib treatment. Advancing age associated with reduced cardiac performance for patients receiving imatinib. We recommend studying the neopterin level in patients with thalassemia major patients with $<1000 \mathrm{ng} / \mathrm{ml}$, and it's relation to the frequency of blood transfusion in major thalassemia patients.

\section{AUTHOR'S CONTRIBUTION}

Concept and collection of data - Y.M. TAHER, A.F. ALWAN. Writing the article and critical review of the article - Shahad F Obeid, H.A. FAWZI. Statistical analysis H.A. FAWZI, Final approval of the article - A.A. Ahmed, A.F. ALWAN, N. Shalaan, Hayder Adnan Fawzi.

\section{CONFLICTS OF INTEREST}

The authors declare that they have no conflicts of interestNone

\section{REFERENCES}

1. Deininger M, Brien SG, Guilhot F, Goldman JM, Hochhaus A, Hughes TP, et al. International randomized study of interferon Vs STI571 (IRIS) 8-year follow up: Sustained survival and low risk for progression or events in patients with newly diagnosed chronic myeloid leukemia in chronic phase (CML-CP) treated with imatinib. Blood 2009; $114: 1126$.

2. Hahn EA, Glendenning GA, Sorensen MV, Hudgens SA, Druker BJ, Guilhot $\mathrm{F}$, et al. Quality of life in patients with newly diagnosed chronic phase chronic myeloid leukemia on imatinib versus interferon alfa plus low-dose cytarabine: Results from the IRIS study. J Clin Oncol 2003;21:2138-46.

3. Gupta M, Dahiya J, Marwaha RK, Dureja H. Therapies in cancer treatment: An overview. Int J Pharm Pharm Sci 2015;7:1-9.

4. Darji AA, Bharadia PD. Chronic myelogenous leukemia: A review and update of current and future therapy. Int J Pharm Pharm Sci $2016 ; 8: 35-46$

5. Kerkela R, Grazette L, Yacobi R, Iliescu C, Patten R, Beahm C, et al. Cardiotoxicity of the cancer therapeutic agent imatinib mesylate. Nat Med 2006;12:908-16.

6. Force T. In reply to cardiotoxicity of the cancer therapeutic agent imatinib mesylate. Nat Med 2007;13:15.

7. Druker BJ, Guilhot F, O'Brien SG, Gathmann I, Kantarjian H, Gattermann N, et al. Five-year follow-up of patients receiving imatinib for chronic myeloid leukemia. New Engl J Med 2006;355:2408-17.

8. Hochhaus A, Druker BJ, Larson RA, O'Brien SG, Gathmann I, Guilhot F. IRIS 6-Year follow-up: Sustained survival and declining annual rate of transformation in patients with newly diagnosed chronic myeloid leukemia in chronic phase (CML-CP) treated with imatinib. Blood 2007;110:25.

9. Kantarjian H, Pasquini R, Hamerschlak N, Rousselot P, Holowiecki J, Jootar S, et al. Dasatinib or high-dose imatinib for chronic-phase chronic myeloid leukemia after failure of first-line imatinib: A randomized phase 2 trial. Blood 2007;109:5143-50.

10. Atallah E, Durand JB, Kantarjian H, Cortes J. Congestive heart failure is a rare event in patients receiving imatinib therapy. Blood 2007:110:1233-7.

11. Freebern WJ, Fang HS, Slade MD, Wells S, Canale J, Megill J, et al. In vitro cardiotoxicity potential comparative assessments of chronic myelogenous leukemia tyrosine kinase inhibitor therapies: Dasatinib, imatinib and nilotinib. Blood 2007;110:4582.

12. Francisco ARG, Alves D, David C, Guerra L, Pinto FJ, Almeida AG, et al. Cardiotoxicity in hematological diseases: Are the tyrosine kinase inhibitors imatinib and nilotinib safe? Cardiovasc Toxicol 2018; doi: 10.1007/s12012-018-9453-3.

13. Maharsy W, Aries A, Mansour O, Komati H, Nemer M. Ageing is a risk factor in imatinib mesylate cardiotoxicity. Eur J Heart Fail 2014; $16: 367-76$ 